\title{
Analysis on NetEase Games Marketing Mode in New Competitive Environment
}

\author{
Xiaowei Zhu ${ }^{1,2}$ and Haoting Song \\ ${ }^{1}$ Wuhan Technology and Business University, China, HuBei, Wuhan, 430065 \\ ${ }^{2}$ Hubei Business Service Development Research Center, China, HuBei, Wuhan, 430065
}

Keywords: Developers; Marketing mode; Informatization; New competitive environment

\begin{abstract}
Products have an increasingly shorter lifetime, so traditional cost model can not be adapted to new environment any more. In order to adapt to such a highly competitive and changeable market, developers are looking for more preferable marketing modes to stimulate customers' consumption desires. Therefore, how to succeed in marketing and occupy the highest market share of the whole market, is a realistic challenge ahead of a large number of online game developers. This thesis aims to provide a comprehensive analysis of the all marketing modes of the NetEase games in today's new competitive environment, combined with practical working experiences. Based on the problems existing in marketing modes, improvement suggestions will be raised in this thesis.
\end{abstract}

\section{The Overview of New Competitive Environment and Marketing Mode}

The Definition of New Competitive Environment. What is the new competitive environment? Marketing competition becomes more vehemence and the shuffle is intensified. The development of internet service industry is stimulated as the rapid expansion of online games. Chinese enterprises have entered into an era that wins through strategy. By the end of 2003, online game developers and online game operators have increased to hundreds and at the same time the types of online game products have also increased to hundreds. Now the market pattern is that a few successful enterprises and games occupy the majority of the market shares and the rest of the niche games occupy a very small market share and wander at the fringes of the market. This kind of market pattern also determines that the operation failed games have to withdraw from the game market eventually. Many effective methods for enterprises now have stuck in bottleneck period.

\section{The Performance of New Competitive Environment}

The Constant Change of Game Operation Pattern.

In order to get a better future in the development of games and get more attention from Chinese market, many foresighted game developers will give their operation right to some operators who have a large number of customers, like NetEase and authorize such a "hypermarket". It is also an important impetus of enterprises to engage in strengthening their operation capability. In addition, many enterprises continue to grow and they have become potential entrants of game operation. For the developers themselves, under the influence of the game they will develop and grow stronger and participate in the operation of game eventually.

More fierce competition.

At present, the main user resources are possessed by few enterprises in each field of internet application in our country, such as Tencent in the field of IM, NetEase and SOHU in the field of Web portal, etc. Such companies can accumulate their user resources through operating games. They become strong is not because of developing games, at first, they just were game operation deputies but gradually they focus on the development of the game and have their own development team, especially the NetEase that is far ahead in this field. Now the competition is increasingly fierce because many developers pay more attention to the market, seek some opportunities and expand their $\mathrm{r}$ and $\mathrm{d}$ team. 
The Definition of Marketing Mode. Marketing mode refers to the different ways and means people used in the process of marketing. Network marketing is the main marketing mode for online game. Especially under the background of the informatization development, most enterprises will implement the product marketing work via the internet.

\section{The Type of Marketing Mode of Online Game.}

Advertising Propulsion Mode.

For users, one of the main ways to know the game is directly through the official website where includes the relevant information of game. At present, $40 \%$ users know the games through official website and it is also the main way for advertising. In addition, knowing from professional game website is equal as knowing from friends. Online game promotion is different from traditional product promotion. The influence of newspapers, television and outdoor advertising is limited, so it will be more effective to place the advertising in the official website, web portals and live broadcast.

Multidirectional Channels Pull Mode.

Internet cafe, college and network operators are typical channels. Through these channels, the internet condition of users are very good, so the success rate to recommend games to the users is increased considerably. When game promoter generalize this game in internet cafe or through phone, most users will listen carefully. Though this way is inefficient, once the users accept and try this game, they will be more interested in this game. However, the manufacturers usually cope with network operators in sharing mode. For college channel, usually students are attracted by organizing game competition and other activities.

Word-of-mouth Mode.

Nowadays in the environment of advertising overflow, lots of people are immune to advertising which lead to weaken the effectiveness of the advertising. At this time, the enterprises will use their friends and relatives to recommend the game to the people around. In that way, the brand will be spread and more people will be attracted to play this game. For the people, they will accept this new product easily through this way to promote and the cost of this way will be lower and the efficient of it will be higher. So word-of-mouth marketing is a double-edged sword, the key of it is to set up a good public praise otherwise it will effect badly.

\section{Current Situation of NetEase Game Marketing Mode in the New Competitive Environment}

The Chinese online game has gained a strong momentum in recent years which has entered into a stage of white-hot competition. Several oligarchs possess over 80 percent of the market shares and a large number of small companies share the rest part. The year 2001 saw the establishment of online game business department in the NetEase and the brand valuation of this department has reached 1.3 billion dollars over 16 years. It makes itself one the world seven big game companies. The market shares of NetEase have always maintained a steady growth, especially when it got the agency of the "World of Warcraft", its market shares has then entered into the first camp. Currently, with its total market shares of $16 \%$, it ranks the third. The mobile game registers $18.14 \%$ of market shares and ranks the second.

Organizing Multi-station Offline Players Appearance. Netease Business Department for 2001 Online Games has formally founded, which is taking a leading position in online game field, has ranked the first online game corporation in China which is able to research and design independently. When their online games in terminal equipment are in vogue, they got a close contact with their users by hosting game-fan meeting. This is a kind of trial and exploration which narrows the distance between users and makers, as well help makers know things that users really want via going further into user groups. Besides, it helps to standardize and formulize, in this way, they can host regular greet-and-meet and game carnival. This kind of marketing mode using platforms increase the connections among users, or between users and operators. Then we talk about offline game-fan meetings. These meetings not only raised Netease Game profile and market influence, but also brought rich income. As the pic2-2 (Netease turnover of offline game-fan meetings) showed, we can see our turnover earned by game-fan meetings has increased from over 
two million yuan in 2009 to over ten million yuan in 2014, six times as much as former situation in recent six years.

Celebrity Endorsement. The NetEase Games boast strong independent research and development powers. Up to now, it has launched 27 games by independent research and development, which includes China's first MMOG the "Chinese Odyssey" with 250 million registered users, as well as the "Fantasy Westward Journey" the online game of double art version whose online users has reached 2.71 million. On May 24, 2010, the news that Jay Zhou who produced a new album of The Era will endorse the "Fantasy Westward Journey" was widely spread among Jay's fans and game players. The message "everyone plays the Fantasy Westward Journey" still remains fresh in the memory of players who are keen on this game at that time. As Jay Chou said that since he has endorsed for the "Fantasy Westward Journey", he has conducted a series of cooperation with the NetEase and brought surprises for the players. When the "super game play" was launched on June 8, the game is quite popular on June 11 when the new service is named after Jay's song "Preface of Lanting". The day when this new service was launched, there were so many players online. Another example is that NetEase's typical game "Fantasy Westward Journey" is adapted to TV play.

Game Live Online. Currently, the very popular live platforms are "Dragon Live", "DouYu TV", "Pandas live" and other small live platforms. As for the Warcraft which is the one of games developed by NetEase, many good players will be employed to play it in the live platform periodically. In that way, more audiences will be attracted to play this game and integrate into the game intuitively. The developers also can promote their games to attract more players through cooperating with live platforms and the good players and live platforms also can get a profit because of the gifts gave by audiences.

\section{Problems Existing in NetEase Game Marketing Mode}

Different Opinions about Appearance Activities. The planning of activities' content is a very difficult things because of the different opinions of players and every time the players will complain it. The official should review themselves if they understand the thought of the players and if the design scheme cover most players and satisfy them. Although China's online game operators have a foundation of profit model and the game crowd scale is very large, the hot of this stage doesn't mean they can profit all the time. When more and more users get bored or lost interest in game meet-and-greet and dissatisfy the equilibrium of the game, the number of users will show the tendency of decrease and the marketing effect also will be reduced considerably. The game designed carefully for meet-and-greet will become useless because the high waste and cost. Take the table 3-1 The Number of Participants of the Player Appearance Activities in 2013-2015 as a example, we can see the participation situation of players in each link of meet-and-greet in recent years and also we can know in recent 3 years the number of participants of each link of meet-and-greet gradually decrease year by year whatever the most attractive links of lottery and question and answer.

Table 3-1 The Number of Participants of the Player Appearance Activities in 2013-2015

\begin{tabular}{|l|l|l|l|l|}
\hline Year & Game Exchange & $\begin{array}{l}\text { Players' } \\
\text { Competition }\end{array}$ & Lottery & $\begin{array}{l}\text { Question and } \\
\text { answer link }\end{array}$ \\
\hline 2013 & 1480 & 1830 & 3440 & 3893 \\
\hline 2014 & 946 & 1230 & 2944 & 2345 \\
\hline 2015 & 537 & 704 & 2300 & 1254 \\
\hline
\end{tabular}

According to the growth rate of great-and-meet sales revenue in recent years, the growth rate after 2011 has been sluggish, with about $1 \%$ increase per year. The highest growth rate is only $37.97 \%$ in 2013 , which lags behind the growth rate of overall game market with $57.4 \%$. 
Besides, as the game companies focus on comparison and game players disperse gradually, the cost for each greet-and-meet keeps increasing. A stadium housing 1,000 person should need about 200,000 RMB, the equipment cost for stage performance should be over millions RMB and the advertising should be about 500,000 RMB. As the meet-and-greet tends to be indulged in ostentation, more and more stars and web celebrities will come on the stage, and the expense for appearance fee is beyond calculation.

Risk of Star Endorsement. First, the celebrity effect has limited effectiveness for a given period of time, because even the most popular stars would have celebrity effect in only a couple of years. Perennial stars like Andy Liu, Jackie Chan and Song zuying are rare. Some sports stars shine brightly for a very short time for all kinds of hindrance. If a "star" falls short of yesterday's glory, the brand itself would become outdated as well. Thus, the celebrity endorsements is risky. Next, there are uncontrollable ethnic and healthy issues. Theoretically, celebrity endorsement is a doubleedged sword whose advantages can not be employed and whose disadvantages can not be avoided. In this view, corporations should always keep an watchful eye in choosing celebrities for the probability of failure is far greater than success.

Live Marketing Separated From Product. The development of online marketing in China is limited by the shortage of talents. Corporations may employ specialized website operators, while they lack of specialized marketing talents. If there lack comparatively comprehensive marketing strategies backstage, audiences would put more attention on game masters but not the games, which may further cause the failure of marketing campaigns even if game masters promoting games by their super skills and good-looking.

\section{The Improvement to the Current Situation of NetEase Game Marketing}

Enrich the Content of the Appearance. First, the campaign should be devised to fit the goal and finally realize it. Second, it should cater to audience's tastes, because they would participating only when they were attracted. Third, set a suitable participating threshold. Fourth, devise interesting participating approaches. Interesting participating approaches can maximize the motivation. It serves as the key point to attract participants other than awards. Fifth, the campaign needs to show emotional resonance. In this way, users can be moved.

Reducing the Risk of Spokesperson. At the beginning, we must improve our ability to manage the celebrities and broaden the range of endorsed celebrities, what's more, to establish faithful users groups on the basis of marketing plans. Next, establish a set of rigorous censorship, accountability system and advertising pre-trial system, so that advertisements can be screened at all levels before display by specialized screening. When facing celebrity endorsements crisis, corporations must notice all the public relations ,news releasing and other information spread ways, actively communicate with the public, admit faults and shoulder the responsibilities, prove your sincere attitudes to get public recognition back. The last one, the cost of celebrity endorsements may be high, corporations should think more about the expenditures on this aspect which takes up only one part of the whole campaign. Other things such as advertisement costs, production costs and print costs must be put into consideration. So, corporations should focus on cost accounting rather than those popular celebrities and game masters. The advantage of "common people" lies on lower costs and less limitations, it may also meet the promotion expectations after further promotion and sophisticated design.

Various Forms of Promotion at Backstage While Living Broadcast. First, soft language promotion on live show platform, when live show, we can expand our influence by original soft language, key words and bullet screens, as well display some targeted articles on the rolling screens to promote. Second, IM promotion. By IM promotion (QQ, UC, MSN, Alitalk) mass texting, we can join targeted groups, and then release related information, or create groups to identify the users. Third, Wechat promotion. It works when sending messages to users who have the greatest engagement. Under these circumstances, the accurate marketing may of use to identify users and send messages according to geographic regions and certain information. By managing specific subscription ID number, we can operate friend circles, and some more users may get involved. 


\section{Conclusion}

This thesis was only targeted on the typical marketing mode of NetEase, so there must have some shortcomings on the research. Chinese online game industry is at a mature and steady stage. On the whole, Chinese online game industry presents unity and compatibility, and gradually formed a complete industry chain which mobilize channel distributors, game cards retailers, Internet service providers (net cafe) and media. Online game operators who take a leading position in the industry chain are becoming more sensible and mature. Meanwhile, online game corporations have build a good relation with major telecommunication corporations and network vendors. China has become the biggest information consumption market worldwide, let alone its online game market. Having the biggest potential game consumption market, online game, the virtual world must be a place where carries other products and services and enable common development and cooperation between different industries. It is suffice to say the future of Chinese online game industry will be bright!

\section{Acknowledgement}

Fund Project: Hubei Provincial Collaborative Innovation Center for Modern logistics and business (Project No.2011A201307)

Fund Project: MOE (Ministry of Education in China) Project of Humanities and Social Sciences (Project No.14YJCZH154)

Funding team: Wuhan Technology and Business University Academic Team (Project No. XSTD2015004)

\section{References}

[1] Shan Zhenghua. Online Virtual Games: Expanded New Areas of Traditional Media Marketing Channels [J]. Publishing Research, 2013, (11): 14-15.

[2] Lei Ming. Experiencing Marketing of the Online Games [J]. Jiangsu Commercial Forum, 2013, (1): $15-16$.

[3] Wang Lijuan. Analysis on Forms and Features of Online Game Advertisement [J]. Art and Design (Theoretical Edition), 2013,(2): 26-27.

[4] GB/T 16159-2016, Marketing Research Principles of China [S]. Beijing: Standards Press of China. 2016.

[5] Diros. Year-end Check of China's Online Game Companies [N]. Xinhua Daily, 2016, 30 (12A): 2010-2016.

[6] Tan Bin. "Darwin Principles" of the Online Game Market [J]. China Internet. 2014, (2): 4-5.

[7] Fu Xiaolong. Research of Advertisement Effect and Design Mode of Online Games [J]. Packaging Engineering, 2015,(12): 92-93.

[8] Yang Peng. An Inductive Analysis of Factors Impacting Consuming Behavior of Online Games [J]. Journal of Beijing University of Posts and Telecommunications (Social Sciences Edition). 2013, (6): 5-7.

[9] Zhang Ling. An Analysis of Spread of Domestic Online Games [J]. Southeast Communication, 2013, (12): 39-40.

[10] Jun Moxiao. An Analysis of Export Trade of Online Games [D]. Nanchang: NanChang Business College of Jiangxi Agriculture University. 2013. 